Tarih Kültür ve Sanat Araştırmaları Dergisi

Revue des Recherches en Histoire Culture et Art

مجلة البحوث التاريخية و الثقافية والفنية
Vol. 6, No. 6, December 2017

Copyright (C) Karabuk University

http://kutaksam.karabuk.edu.tr

\title{
DOI: 10.7596/taksad.v6i6.1245
}

Citation: Namin, H. S. (2017). An Investigation into the Effect of Using Geometric and Non-Geometric Shapes on the Desirability of Human Character Stylization in Children's Narrative Fiction Illustration. Journal of History Culture and Art Research, 6(6), 194-206. doi:http://dx.doi.org/10.7596/taksad.v6i6.1245

\section{An Investigation into the Effect of Using Geometric and Non-Geometric Shapes on the Desirability of Human Character Stylization in Children's Narrative Fiction Illustration}

\author{
Hajar Salimi Namin ${ }^{1}$
}

\begin{abstract}
This study aims to investigate the effect of teaching the using of geometric and non-geometric shapes on human character stylization created by undergraduate graphic design students with poor performance in illustration of children's narrative fiction. The research methodology includes an experimental research by pre- and post-testing with test group in the next stage. Statistical population of the study consists of female undergraduate sophomores of graphic design at Faculty of Arts, Al-Zahra University in 2017. The students were first subjected to pretesting, and then the training package was provided to them and they were again subjected to testing. 35 students are selected to conduct the research. The tools used in this study include files, materials in the books, articles and related sites, experiments and appraisal forms. The results show that there is a significant difference between the pre-test and post-test. The independent variable thus creates a significant difference in the test group and is able to improve the human character stylization implemented by undergraduate students of graphic design at the post-test stage. Therefore, it is suggested to employ using of geometric and non-geometric shapes in order to teach human character stylization to the students.
\end{abstract}

Keywords: Illustration, Illustration for children's narrative fiction, Stylization, Human character stylization.

\footnotetext{
${ }^{1}$ Faculty Member, School of Art, Al-Zahra University. E-mail: hajar_salimi@yahoo.com
} 


\section{Introduction}

The present research is the result of educating narrative fiction illustration to undergraduate students of graphic design. In students' art works within the scope of human character stylization, the issue of inability to create appropriate human character stylization in children's narrative fictions illustration is well exposed.

So based on "human character stylization" model in paper entitled Presenting a Model for Stylization for human character in Children's Narrative Fiction Illustration (2017), the students' works were evaluated and it became clear that the students just fail to use the simplification of line, form, and relationships of space and color, etc. or use these factors inappropriately or inadequately; i.e. they present inappropriate human character stylization.

In the modern world of today, the subject matter of illustration has been increasingly regarded by illustrators, publishers, audience, etc. This is while most of the student of graphic design either neglect to present any individual human character stylization in their art works or just copy those originally created by famous illustrators.

Therefore, the main objective of the present research is to propose a training package for evaluating and improving training in human character stylization for the children's narrative fictions illustration for undergraduate students of graphic design who are weak in human character stylization appropriately.

Investigations on academic research engines ended up finding only one paper that has its focus particularly on the axial concept studied in the present research. The difference between the present research and the mentioned was that, the present research looks forward presenting a training package for enhancing the stylization of human character; as such, this seems to be a novel topic in art studies in Iran and the world.

Generally speaking, the present research looks forward to answer the following question:

What is the influence of using geometric and non-geometric shapes on of human character stylization in children's narrative fiction illustration?

In order to achieve this goal, in a first step, relying on six years of experience in teaching the topic, a training package which included four innovative techniques was designed for stylization; these techniques included the use of a variety of geometric and non-geometric shapes in the process of stylization.

The package was then provided to the test group and then they were subjected to testing. Works by the statistical population were surveyed according to the model, with conclusions drawn finally.

In Section 1 a review is given on basic concepts of illustration, narrative fiction illustration, and stylization followed by presenting a background for the research. Section 2 delivers the research question and methodology. In Section 3, the research results are reported, followed by discussion, conclusion and some recommendations.

\section{Literature review}

\subsection{Basic concepts}

\section{Illustration}

Illustration is neither an art nor a graphic design totally; but, as a discipline, it sits somewhere between art and graphic design. Indeed, for many practitioners it can feel closer to end of this spectrum than the other (Zeegen, 2009: 6). However, it holds a distinct core which constitutes its 'raison d'être'. Illustration is a way of communication to carry a specific contextualized message to an audience. It is rooted in an 
objective need, which has either been generated by the illustrator or a commercial based client to fulfill a particular task. It is the measure and variety of these different tasks that makes the discipline of illustration such an influential visual language (Male, 2007: 10).

\section{Stylization}

Stylization refers to visual depictions that use simplified ways to represent objects or scenes without attempting to depict them in a full precise and accurate representation. Instead, it prefers a unique expressive depiction. More technically, it has been defined as "the decorative generalization of figures and objects by means of various conventional techniques, including the simplification of line, form, and relationships of space and color" (the Great Soviet Encyclopedia).

Even in art that is in general attempting mimesis or "realism", a degree of stylization is very often found in details, and especially figures or other features at a small scale (Holloway, 1983: 30).

'Style' is the distinctive visual language that identifies one's 'mark' or personal iconography (covers the subject and the content of the work) (Zeegen, 2012: 173). It is that particular feature or quality that determines what kind of illustration one is associated with. It should also define one's placement within a visual, illustration genre. Like music, literature and fine art, an applied art and design discipline such as illustration will comprise numerous variations, themes and treatments. Some will represent an adherence to a contemporary trend or fashion and others will be more traditional (Male, 2007: 50).

A historical and contemporary overview of illustration will depict seemingly hundreds of styles. However, in broad terms, there are just two forms of imagery. All variations of visual language will be placed within one of these. Literal illustrations tend to represent pictorial truths. Here there is generally an accurate description of reality and even if the image depicts narrative fiction of a fantastical or dramatic nature, the accent is on creating a scene that is credible. The second form of illustration can be described as conceptual. Here we can have metaphorical applications to the subject or visual depictions of ideas or theories. The images may contain elements of reality, but as a whole take a different form of being (Ibid).

Both forms of illustration can be applied to all five contexts of practice; information, commentary, narrative fiction, persuasion, identity. However, some styles are best suited to specific or particular uses. It can broadly be agreed upon that such is the versatility of illustration regarding the breadth of visual language that as an applied art form it can depict anything and in any style (Ibid: 51).

However, it is important to regard that stylization has to be appropriate for the subject matter, the context of operation and ensure a considered receptivity for the audience. Illustration practice is individualistic regarding visual language and there can be far reaching and challenging aspects to one's style, often to the point of utilizing more than one (Ibid).

\section{Illustration for narrative fiction}

Storytelling is often considered a prerequisite to provide visual representation of narrative fiction. Today, narrative fictional illustration is mainly encountered in children's books, graphic novels and comic strips, and specialist publications such as thematic compilations, containing mythology, gothic tales and fantasy (Male, 2007: 138).

The factors of illustration for narrative fiction are character, plot, stylization, theme, style, structure, form, genre, narration, tense and other related like audience, author, idea, creativity, imagination, fiction writing, storytelling, storyboard, technique, drawing, composition, color, space, book cover, layout, ... but essential one's are idea, characteri, stylization, storyboardii, composition iii, technique and color. 


\subsection{Research background}

After examining academic search engines, I ended up with three books and one paper that are most relevant. These research works were studied, with their results presented in the following.

Illustration: A Theoretical \& Contextual Perspective (2007) presents a brief discussion on stylization in a section entitled as The Nature of Imagery. In the present research, this title is reviewed and investigated.

A Medieval Book of Beasts: The Second-Family Bestiary, Commentary, Art, Text and Translation (2006), The Slumber of Apollo: Reflections on Recent Art, Literature, Language and the Individual Consciousness (1983) also present a brief discussion on stylization. In the present research, these two titles are reviewed and investigated.

Presenting a Model for Stylization for human character in Children's Narrative Fiction Illustration (2017) presents a model for human character stylization. In the present research, this title is reviewed and investigated. The difference between the present research and the mentioned research was that, the present research looks forward presenting a training package for enhancing the stylization of human character.

Despite the attempt made, no further book, paper or research activity was found where the subject matter of the present research was particularly discussed; as such, this seems to be a novel topic in art studies in Iran and the world.

\section{Research methodology}

\subsection{Research question}

What is the influence of using geometric and non-geometric shapes on of human character stylization in children's narrative fiction illustration?

\subsection{Data collection method}

In the present research, required data was collected via library studies and field surveys (appraisal form). Research terms, concepts, training packages, test were prepared by considering existing literature on virtual and physical spaces in combination with such methods as text-reading, note-taking, and picturereading, and field surveys were undertaken to sample the students.

\subsection{Data collection instrument}

In the present research, notes, materials published in text books, papers, journals, and related websites, and also tests and appraisal forms were used to collect the required data.

\subsection{Research method}

1. In a first step, relying on six years of experience in teaching the topic, a training package was designed for enhancing the stylization of human character based on the presented model (Table 1). 
Table 1: Model of sub-indexes of human character stylization in children's narrative fictions illustration (Salimi Namin, 2017)

\begin{tabular}{|c|c|c|c|}
\hline \multirow{17}{*}{ 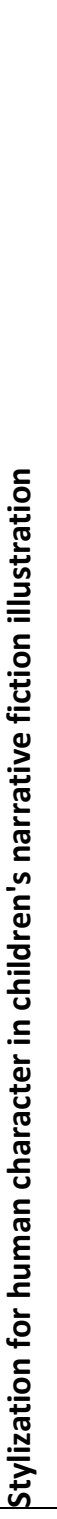 } & \multirow{7}{*}{$\begin{array}{l}\text { 1. Conceptual } \\
\text { stylization }\end{array}$} & \multirow{4}{*}{$\begin{array}{l}\text { 1. Simplification in } \\
\text { spatial relations }\end{array}$} & 1. Presentation of the most obvious silhouette \\
\hline & & & 2. Presentation of the simplest view angle \\
\hline & & & $\begin{array}{l}\text { 3. Presentation of simplification in figure, } \\
\text { movements, and poses }\end{array}$ \\
\hline & & & 4. Presentation of simplification in details \\
\hline & & $\begin{array}{l}\text { 2. Simplifications in } \\
\text { line, shape and form }\end{array}$ & $\begin{array}{l}\text { Presentation of simple lines or simple or geometrical } \\
\text { shapes and/or presentation of simple or geometrical } \\
\text { forms }\end{array}$ \\
\hline & & 3. Simplification in & 1. Presentation of flat or briefly toned colors \\
\hline & & color & 2. Providing simple colors \\
\hline & \multirow[t]{10}{*}{ 2. Literal stylization } & \multirow{5}{*}{$\begin{array}{l}\text { 1. Simplification in } \\
\text { spatial relations }\end{array}$} & 1. Presentation of the most obvious silhouette \\
\hline & & & 2. Presentation of the simplest view angle \\
\hline & & & $\begin{array}{l}\text { 3. Presentation of simplification in figure, } \\
\text { movements, and poses }\end{array}$ \\
\hline & & & 4. Presentation of simplification in details \\
\hline & & & $\begin{array}{l}\text { 5. Presentation of proportionalities among different } \\
\text { components and also between the components and } \\
\text { the whole according to those of the real model }\end{array}$ \\
\hline & & \multirow[t]{2}{*}{$\begin{array}{l}\text { 2. Simplifications in } \\
\text { line, shape and form }\end{array}$} & $\begin{array}{l}\text { 1. Presentation of simple lines or simple or } \\
\text { geometrical shapes and/or presentation of simple or } \\
\text { geometrical forms }\end{array}$ \\
\hline & & & $\begin{array}{l}\text { 2. Presentation of simplification in the form, shape, } \\
\text { and line based on the real model }\end{array}$ \\
\hline & & \multirow{3}{*}{$\begin{array}{l}\text { 3. Simplification in } \\
\text { color }\end{array}$} & 1. Presentation of flat or briefly toned colors \\
\hline & & & 2. Presentation of simple colors \\
\hline & & & $\begin{array}{l}\text { 3. Presentation of colors in stylization based on the } \\
\text { colors of the real model }\end{array}$ \\
\hline
\end{tabular}

2. The training package was presented to the test group.

3. Test was performed.

\section{Statistical population}

This research was performed as a part of a course entitled as illustration I on 35 girl sophomores of graphic design at the School of Art of Al-Zahra University in 2017. The students had enrolled at the university in fall 2014.

These students had passed the following related course within the past two years: Graphic Design I (teacher, Mahbubeh Mohades Madari'), Introduction to the illustration (teacher, Hajar Salimi Namin), illustration I (teacher, Morteza Asadi), Colors and compositions (teacher, Abolfazl Hemmati).

Sample size 
Experimental group: 35 individuals

Sampling method

Considering the small size of the statistical population, the entire population was surveyed.

4. Test results were surveyed.

5. Conclusions were drawn.

As such, the present study is a "survey" research in terms of both its nature and methodology.

\subsection{Experimental design}

The test group received a training package which was designed and delivered to them as follows:

Training package:

Teaching four creative techniques of stylization in four consecutive weeks (one technique per week):

1. Stylization by accidental non-geometric ${ }^{\text {iv }}$ shapes technique: In order to achieve the proper shape in the illustration, instead of using the usual tools of pencil and white paper, scissors and black paper be used; that is, instead of showing the phenomena with pencil on paper, cut it off paper with scissors. In this technique, accident plays an important role, that is to say, while cutting the paper, look for the desired non-geometric shape, rather than cutting a pre-determined non- geometric shape. (figure 1)

2. Stylization by selective non-geometric shapes technique: In order to achieve the proper shape in the illustration, non-geometric shapes be used, that is, non-geometric shapes from the surrounding environment be selected and used as shapes for stylization of the phenomena. (figure 2)

3. Stylization by geometric ${ }^{v}$ shapes technique: In order to achieve the proper shape in the illustration, the geometric shapes be used such as circle, triangle, square, trapezoid, ellipse, rhombus, rectangle, etc. (figure 3)

4. Stylization by geometric shapes without curvature: In order to achieve the proper shape in the illustration, instead of using plain paper, graph paper be used, that is, instead of drawing on an unlined paper, the phenomena be drawn on vertical and horizontal lines and square diameters of graph paper. (figure 4)

\section{Observations and results}

\subsection{Real test conditions}

It should be noted that before the pre-test and test, each student first photographed her grandmother and drew from the photos. In the stages of pre-test and receiving the training package and examining the students' work, their works included sketch from the head of character.

\section{Pretest:}

The experiment group consisted of 35 students who first participated in the pre-test.

In the pre-test, the stylization of the head of the character of the old woman (the main character in rolling pumpkin story) was done based on the head of the student's grandmother. 


\section{Post-test:}

The experimental group consisted of 35 students who participated in the post-test after receiving the training package in four sessions.

In the post-test, the stylization of the head of the old woman character in the rolling pumpkin story (the main character) based on the student's grandmother's head was carried out in the fifth session, after the introduction of stylization concept and receiving the training package in 4 sessions of 135 minutes; which means each student selected one of the works she drew during the four training sessions, and completed it as the post-test full effect and then drew the body of the character.

\subsection{Observations}

In this section, example works done by students are presented:

- $\quad$ Pretest and post-test stage of 4 students (Figures 1, 2, 3, 4)

- $\quad$ Evaluation table for the pretest and evaluation table for the post-test and description of stylization evaluation for one of the students (Tables 2, 3)

- $\quad$ The final works of 6 students (Figures 5 and 6 )
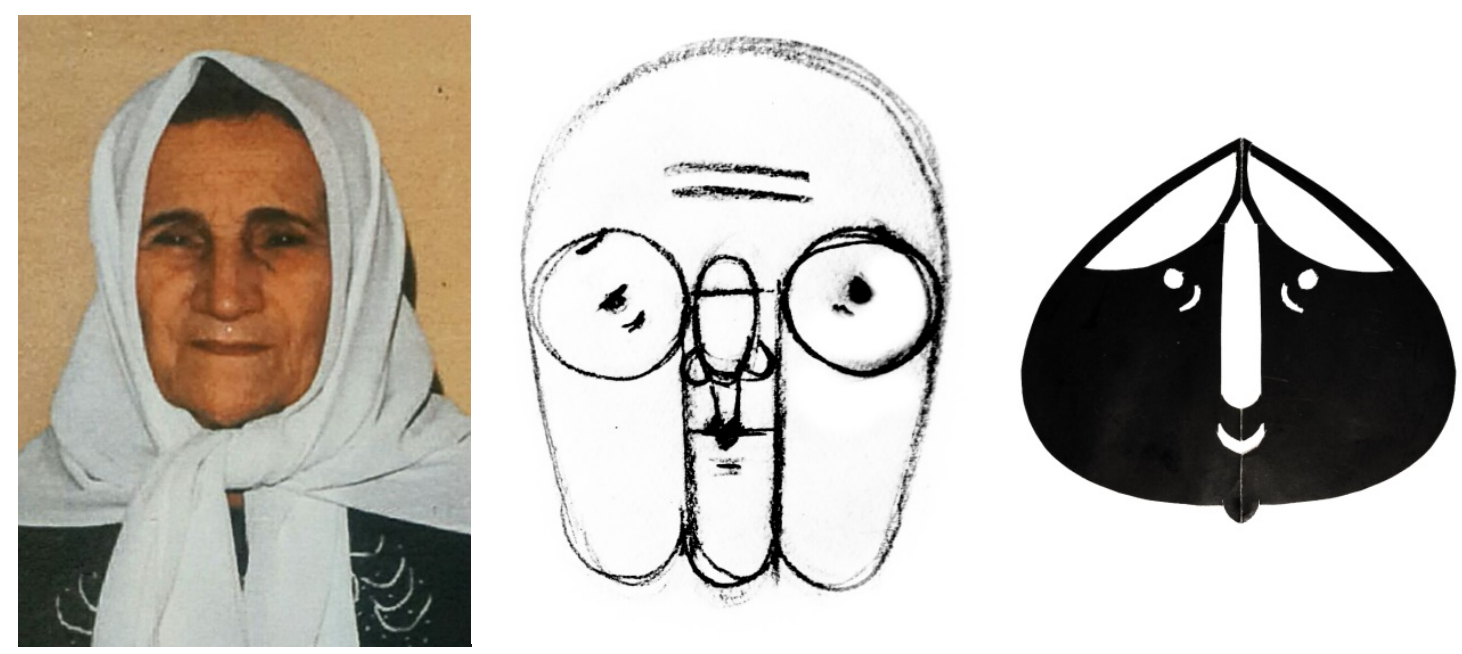

Figure 1: Photo of grandmother, Pretest, post-test (by Zahra Tafazoli): stylization by accidental nongeometric shapes technique. 

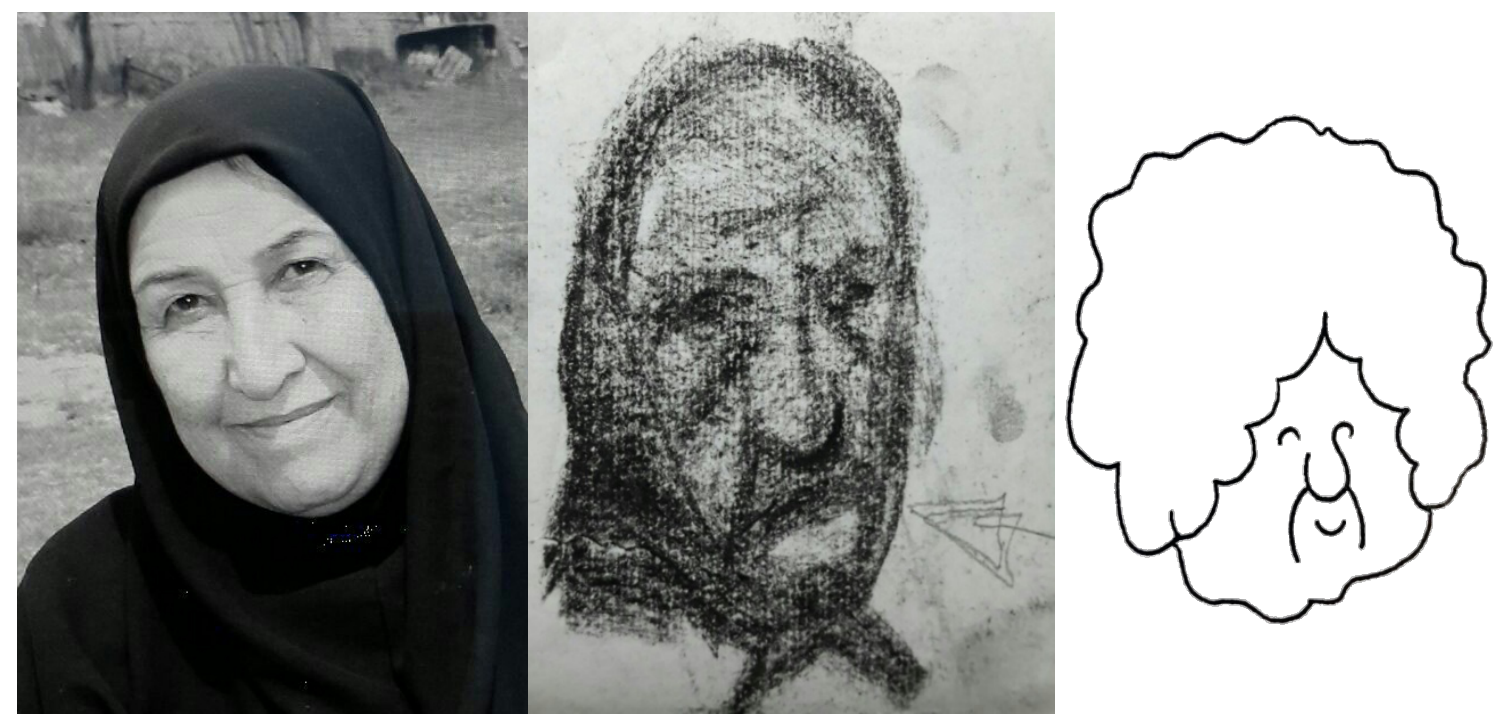

Figure 2: Photo of grandmother, Pretest, post-test (by Mahta Salehi): Stylization by optional nongeometric shapes technique (selection of the pine fruit as the main shape of the face)
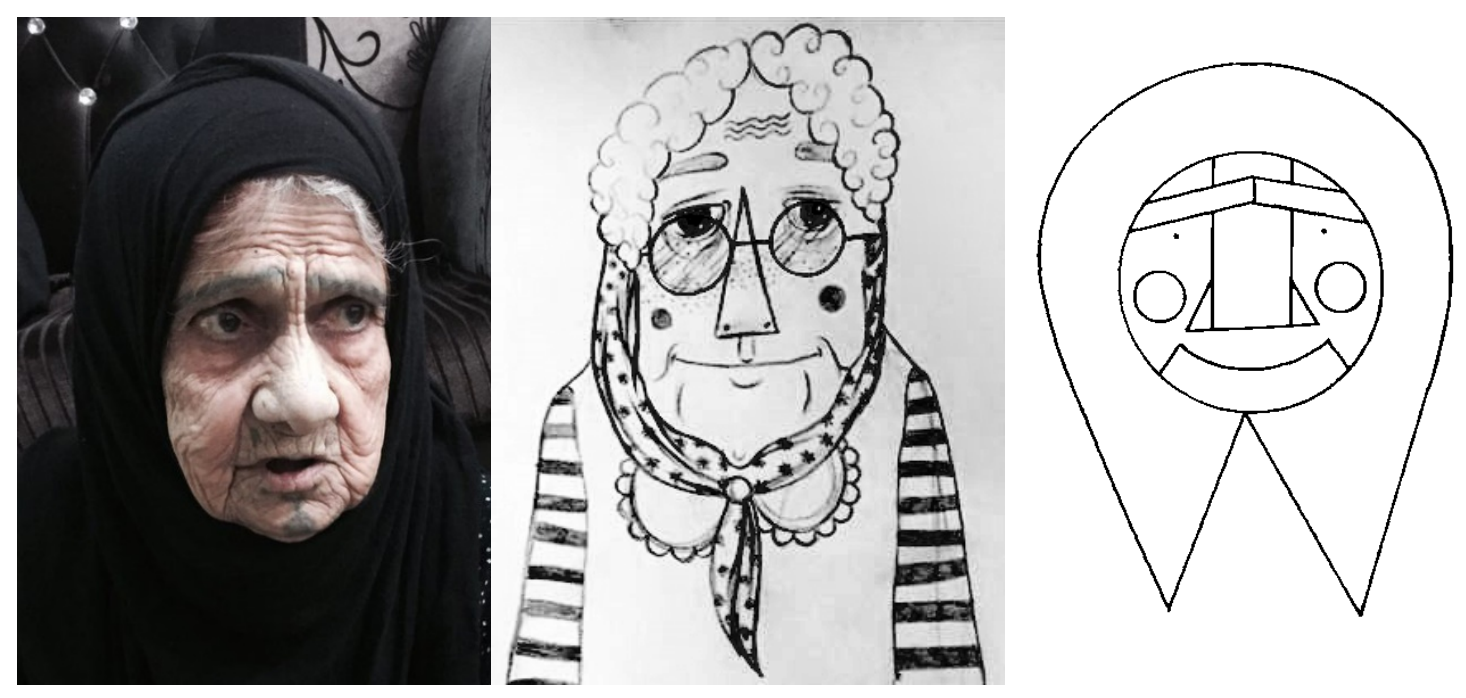

Figure 3: Photo of grandmother, Pretest, post-test (by Donya Ghanavati Zadeh): Stylization by geometric shapes technique. 

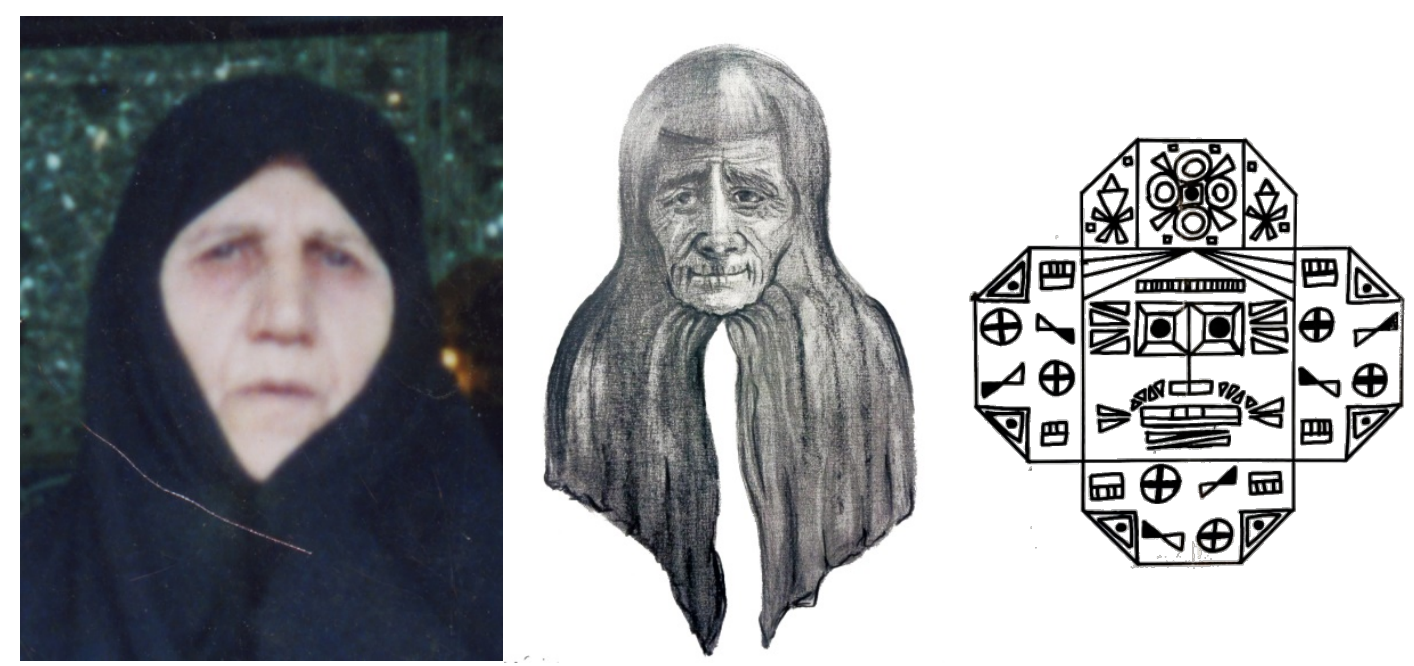

Figure 4: Photo of grandmother, Pretest, post-test (by Sanam Tabari): Stylization by geometric shapes without curvature.

Table 2: Pretest, Sanam Tabari

\begin{tabular}{|c|c|c|c|c|c|c|}
\hline & $\begin{array}{l}\text { Stylization for human character in children's narrative fiction } \\
\text { illustration }\end{array}$ & 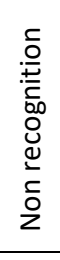 & 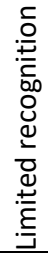 & 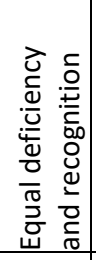 & 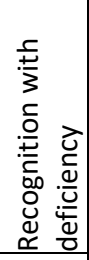 & 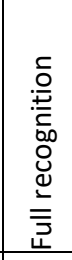 \\
\hline 1 & 1. Presentation of the most obvious silhouette & 1 & & & & \\
\hline 2 & 2. Presentation of the simplest view angle & 1 & & & & \\
\hline 3 & 3. Presentation of simplification in figure, movements, and poses & 1 & & & & \\
\hline 4 & 4. Presentation of simplification in details & 1 & & & & \\
\hline 5 & $\begin{array}{l}\text { 5. Presentation of proportionalities among different components and } \\
\text { also between the components and the whole according to those of the } \\
\text { real model }\end{array}$ & 1 & & & & \\
\hline 6 & $\begin{array}{l}\text { 1. Presentation of simple lines or simple or geometrical shapes and/or } \\
\text { presentation of simple or geometrical forms }\end{array}$ & 1 & & & & \\
\hline 7 & $\begin{array}{l}\text { 2. Presentation of simplification in the form, shape, and line based on the } \\
\text { real model }\end{array}$ & 1 & & & & \\
\hline 8 & 1. Presentation of flat or briefly toned colors & 1 & & & & \\
\hline 9 & 2. Presentation of simple colors & 1 & & & & \\
\hline 10 & $\begin{array}{l}\text { 3. Presentation of colors in stylization based on the colors of the real } \\
\text { model }\end{array}$ & 1 & & & & \\
\hline
\end{tabular}


How to evaluate sub-indexes:

Since the model has two literal and conceptual branches, and in fact, stylization in one artwork is based on one of these two, therefore, since the students have stylized their grandmother, the literal branch was examined;

Sub-indexes of 1-10: Due to no presentation in the work, it was evaluated as non-recognition.

Table 3: Post-test, Sanam Tabari

\begin{tabular}{|c|c|c|c|c|c|c|}
\hline & $\begin{array}{l}\text { Stylization for human character in children's narrative fiction } \\
\text { illustration }\end{array}$ & 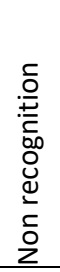 & 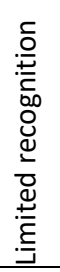 & 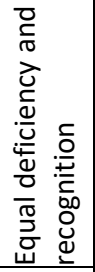 & 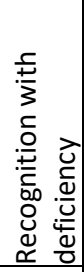 & 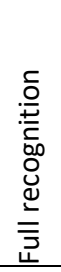 \\
\hline 1 & 1. Presentation of the most obvious silhouette & & & & & 1 \\
\hline 2 & 2. Presentation of the simplest view angle & & & & & 1 \\
\hline 3 & 3. Presentation of simplification in figure, movements, and poses & 1 & & & & \\
\hline 4 & 4. Presentation of simplification in details & & & & & 1 \\
\hline 5 & $\begin{array}{l}\text { 5. Presentation of proportionalities among different components and } \\
\text { also between the components and the whole according to those of the } \\
\text { real model }\end{array}$ & & & & & 1 \\
\hline 6 & $\begin{array}{l}\text { 1. Presentation of simple lines or simple or geometrical shapes and/or } \\
\text { presentation of simple or geometrical forms }\end{array}$ & & & & & 1 \\
\hline 7 & $\begin{array}{l}\text { 2. Presentation of simplification in the form, shape, and line based on } \\
\text { the real model }\end{array}$ & & & & & 1 \\
\hline 8 & 1. Presentation of flat or briefly toned colors & 1 & & & & \\
\hline 9 & 2. Presentation of simple colors & 1 & & & & \\
\hline 10 & $\begin{array}{l}\text { 3. Presentation of colors in stylization based on the colors of the real } \\
\text { model }\end{array}$ & 1 & & & & \\
\hline
\end{tabular}

How to evaluate sub-indexes:

1. Due to the presentation of the whole character, it was evaluated as full-recognition in the work.

2. Due to the presentation of the whole character, it was evaluated as full-recognition in the work.

3. Due to no presentation in the work, it was evaluated as non-recognition.

4. Due to the presentation of the whole character, it was evaluated as full-recognition in the work.

5. Due to the presentation of the whole character, it was evaluated as full-recognition in the work.

6. Due to the presentation of the whole character, it was evaluated as full-recognition in the work.

7. Due to the presentation of the whole character, it was evaluated as full-recognition in the work.

8. Due to no presentation in the work, it was evaluated as non-recognition.

9. Due to no presentation in the work, it was evaluated as non-recognition. 
10. Due to no presentation in the work, it was evaluated as non-recognition.
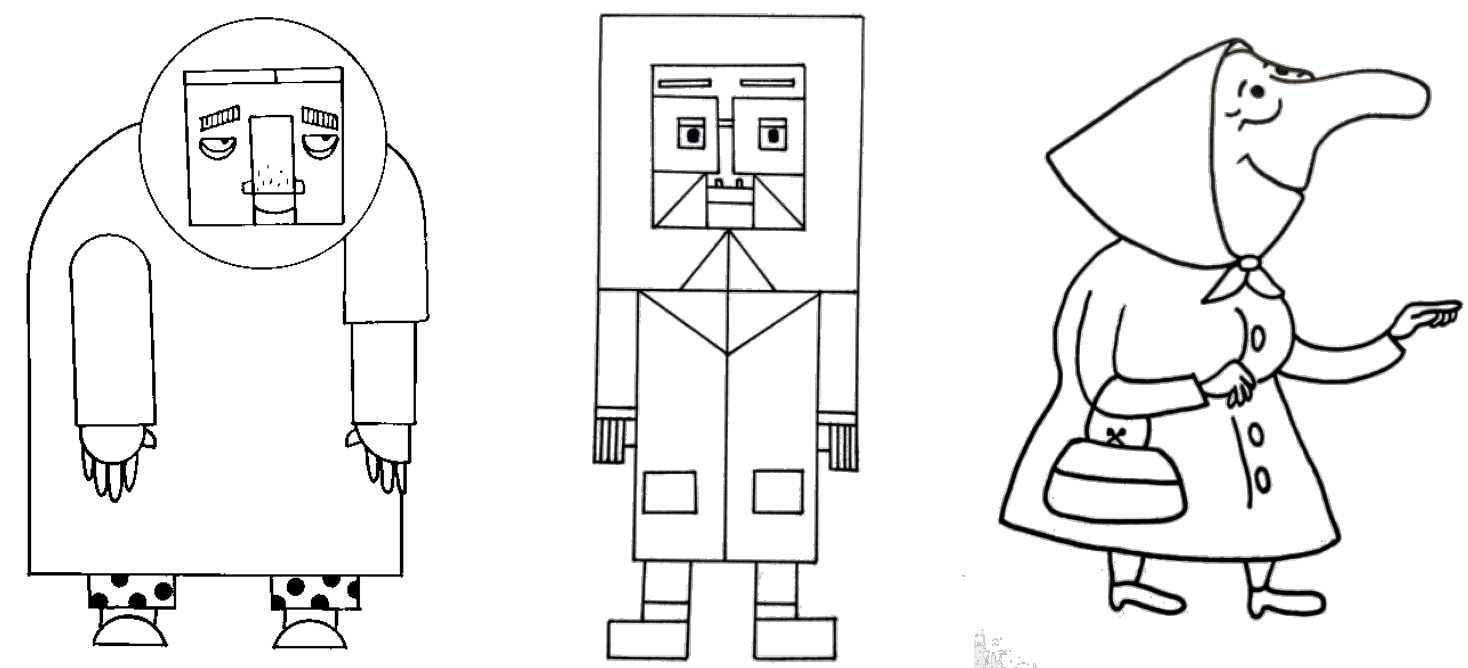

Figure 5: Grandmother's character from left to right: Saideh Punaki, Anashe Sayadian, Mahshad Agha Mirkarimi
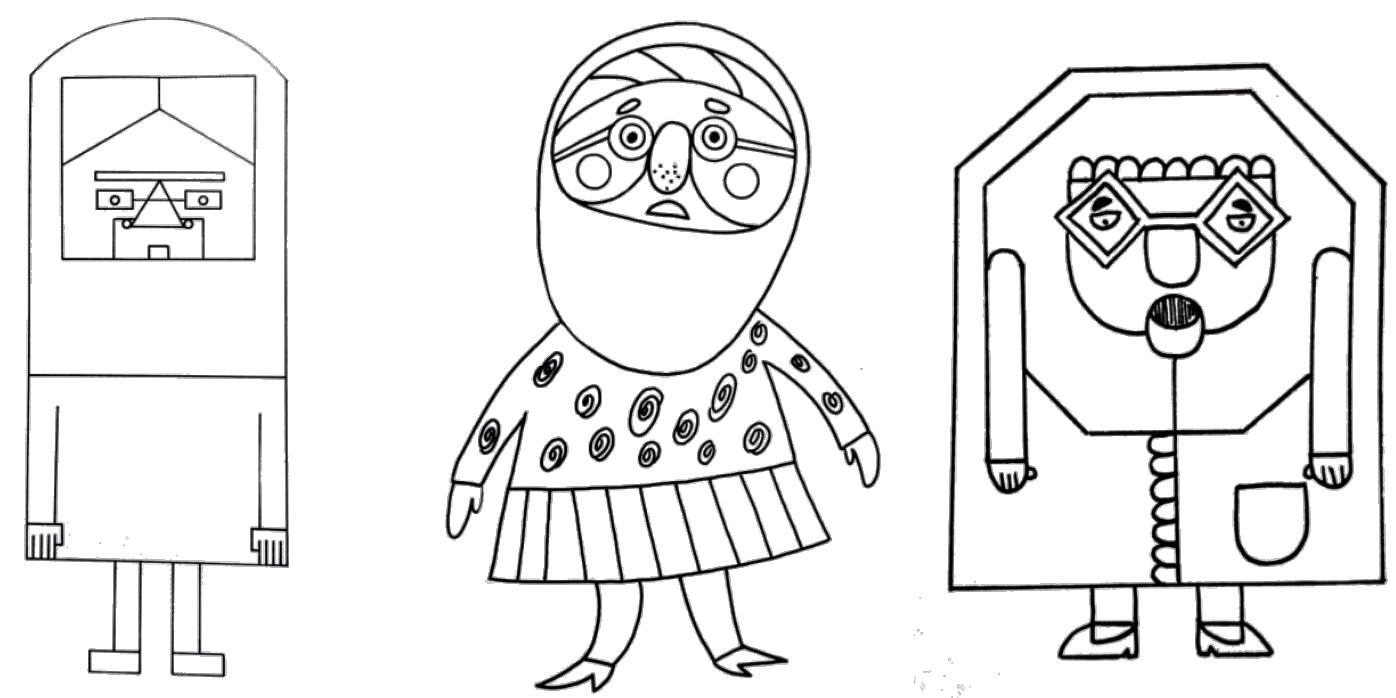

Figure 6: Grandmother's character from left to right: Sara Beyt Safi, Fatemeh Manafi, Fatemeh Hakimi

\subsection{Research findings}

The results of this test show that:

Before presenting the training package, $100 \%$ of the members of the statistical community had nonrecognition; but after the training, this value has reached $45.71 \%$. Also, $33.71 \%$ of the students had limited-recognition after receiving the training package, which was zero percent before the package was presented. $20.57 \%$ of students had also full-recognition which was zero percent before receiving the package. As a result, considering the $118.75 \%$ reduction of non-recognition and the $100 \%$ increase in the limited-recognition, as well as the $100 \%$ increase in full-recognition, the training package has been effective on the desirability of human character stylization in the works of graphic design students and increased it. 


\section{Discussion and conclusion}

The purpose of this study was to investigate the effectiveness of using geometric and non-geometric shapes in stylization of human characters by graphic design undergraduates who had weakness in stylization desirable human characters for children's narrative fiction illustration. The results of the study showed that teaching the use of geometric and non-geometric shapes is an effective intervention for improving the performance of students in 'human characters' stylization. In explaining this finding, it can be said that the use of geometric and non-geometric shapes in stylization is one of the main methods of human character stylization. One of the main problems of students with unfavorable stylization of human characters is their lack of related skills in illustration courses and their prerequisites at the university, so it seems that before characterization unit, a prerequisite unit of study the human character stylization is necessary. Since learning to human character stylization in the illustration of children's narrative fiction course dynamically leads to learning stylization in other characters and phenomena as well as learning to stylization characters in adolescents and adult's narrative fiction illustration. Thus, weakness in this skill in general leads to a lack of or weakness of using desirable stylization by the illustrators, so training the use of geometric and non-geometric shapes is essential for solving stylization problem or inability.

It is also suggested that in teaching human character stylization to students in the illustration course, other educational packages be designed for them and their effectiveness be examined. It is also suggested that for teaching of other character stylization and phenomena (non-human) to students in the illustration course, the effectiveness of the educational package provided in this article be examined.

The present research was limited to the fact that the statistical population was limited to girls.

\section{References}

Clark, Willene B. (2006). A Medieval Book of Beasts: The Second-Family Bestiary, Commentary, Art, Text and Translation. Boydell Pres.

Holloway, John (1983). The Slumber of Apollo: Reflections on Recent Art, Literature, Language and the Individual Consciousness. Cambridge University Press.

Male, Alan (2007). Illustration A Theoretical \& Contextual Perspective. Switzerland: AVA Publishing.

Salimi Namin, Hajar (2017). Presenting a Model for Stylization for human character in Children's Narrative Fiction Illustration. International Journal of Scientific Study, (Electronic version).

The Great Soviet Encyclopedia, (3 ${ }^{\text {rd }}$ ed.). (1970). Soviet state.

Wiedemann, Julius (2009). Illustration Now, Translated by Hana Dabzad. Tehran: Aban-Ketab Pub.

Zeegen, Lawrence (2009). What is illustration? Switzerland: Roto Vision.

Zeegen, Lawrence (2012). The Fundamentals of illustration. Switzerland: AVA publishing. 


\section{End Notes}

'A character (sometimes known as a fictional character) is a person or other being in a narrative fiction work of art.

ii A storyboard is a graphic organizer in the form of illustrations or images displayed in sequence for the purpose of pre-visualizing a motion picture, animation, motion graphic or interactive media sequence.

iii In the visual arts, composition is the placement or arrangement of visual elements or ingredients in a work of art, as distinct from the subject. It can also be thought of as the organization of the elements of art according to the principles of art.

iv. Non geometric shapes can be defined as shapes with irregular contours, and whose edges are not straight.

v. Geometric shapes are shapes with regular contours and straight edges such as squares, triangles, or circles. 